\title{
USO DE SUBSTÂNCIAS PSICOATIVAS ENTRE DISCENTES DE MEDICINA DA UNIVERSIDADE FEDERAL DO AMAPÁ EM 2018
}

\section{ARTIGO ORIGINAL}

DIAS, Cláudio Alberto Gellis de Mattos ${ }^{1}$

FACCO, Lucas $^{2}$

FECURY, Amanda Alves ${ }^{3}$

MELO, Felipe Rodrigues Martins de ${ }^{4}$

AZEVEDO, Eduardo José Lobato de ${ }^{5}$

RIZZI, Ana Carolina Miranda ${ }^{6}$

OLIVEIRA, Euzébio de ${ }^{7}$

DENDASCK, Carla Viana ${ }^{8}$

${ }^{1}$ Biólogo, Doutor em Teoria e Pesquisa do Comportamento, Professor e pesquisador do Programa de Pós-Graduação em Educação Profissiional e Tecnológica (PROFEPT), Instituto Federal do Amapá (IFAP).

2 Discente do Curso de Medicina da Universidade Federal do Amapá (UNIFAP).

${ }^{3}$ Biomédica, Doutora em Doenças Tropicais, Professora e pesquisadora do Curso de Medicina da Universidade Federal do Amapá (UNIFAP).

${ }^{4}$ Médico, Universidade Federal do Amapá (UNIFAP).

${ }^{5}$ Médico, Universidade Federal do Amapá (UNIFAP).

${ }^{6}$ Médica, Universidade Federal do Amapá (UNIFAP).

7 Biólogo, Doutor em Doenças Topicais, Professor e pesquisador do Curso de Educação Física da Universidade Federal do Pará (UFPA).

8 Teóloga, Doutora em Psicanálise, pesquisadora do Centro de Pesquisa e Estudos Avançados- CEPA. 
SILVA, Anderson Walter Costa ${ }^{9}$

SILVA, Alceu dos Santos ${ }^{10}$

CARDOSO, Rosilene Ferreira ${ }^{11}$

ARAÚJO, Maria Helena Mendonça ${ }^{12}$

DIAS, Cláudio Alberto Gellis de Mattos. Uso de substâncias psicoativas entre discentes de medicina da Universidade Federal do Amapá em 2018. Revista Científica Multidisciplinar Núcleo do Conhecimento. Ano 05, Ed. 05, Vol. 13, pp. 21 31. Maio de 2020. ISSN: 2448-0959, Link de acesso: https://www.nucleodoconhecimento.com.br/saude/discentes-de-medicina

\section{RESUMO}

As substâncias psicoativas, também denominadas de substâncias psicotrópicas, são produtos os quais detém a capacidade de promover estímulos ou alterações sensoriais, influenciando emoções e o nível de consciência de quem as usa. O objetivo deste estudo foi analisar o uso de substâncias psicoativas entre discentes de medicina da Universidade Federal do Amapá (UNIFAP) em 2018. Foi realizado estudo transversal quantitativo e qualitativo, que utilizou uma amostra de conveniência, não probabilística, de estudantes universitários. Nesta universidade, entre os discentes de Medicina, notou-se que o uso de psicotrópicos se dá, principalmente, pela utilização

${ }^{9}$ Médico, Professor e pesquisador do Curso de Medicina da Universidade Federal do Amapá (UNIFAP).

${ }^{10}$ Médico, Professor e pesquisador do Curso de Medicina da Universidade Federal do Amapá (UNIFAP).

11 Médica, Doutora em Ciências Médicas, Professora e pesquisadora do Curso de Medicina da Universidade Federal do Amapá (UNIFAP).

12 Médica, Professora e pesquisadora do Curso de Medicina da Universidade Federal do Amapá (UNIFAP). 
de álcool e analgésicos. No contexto médico, por conta do acesso facilitado às drogas de prescrição, a utilização das mesmas é muito mais ampla nesse público de profissionais e acadêmicos, sendo que o uso de tais substâncias é, por vezes, ocultado e existe uma dificuldade em falar sobre e procurar auxílio.

Palavras-chave: Universitários, substância psicoativa, medicina.

\section{INTRODUÇÃO}

As substâncias psicoativas, também denominadas de substâncias psicotrópicas, são produtos os quais detém a capacidade de promover estímulos ou alterações sensoriais, influenciando emoções e o nível de consciência de quem as usa. Seu estímulo pode ser diferente de pessoa para pessoa, uma vez que, embora organicamente similares, os seres humanos possuem características individuais. Além disso, fatores que costumam ser determinantes para o grau da estimulação sensorial são a quantidade e o tipo do psicotrópico, além do contexto no qual for utilizado (BRASIL, 2017).

No Brasil, além das substâncias ilícitas (Anfetaminas, maconha, cocaína, crack, heroína e outras), existe um amplo consumo de drogas lícitas, como álcool, tabaco e analgésicos (BRASIL, 2017). Muitos acreditam que a utilização dessas drogas é quase exclusiva do público juvenil, porém, de forma errônea, uma vez que o índice de idosos que as usam, de forma crônica, tem aumentado (DINIZ et al., 2017).

Tais substâncias podem ocasionar variados tipos de reações no sistema nervoso do indivíduo, podendo ser depressoras, causando diminuição das atividades do sistema nervoso, reduzindo fatores importantes como a capacidade de foco, atenção e raciocínio (álcool, tranquilizantes, heroína e outros). Podem, também, ser alucinógenas, alterando a realidade percebida pelos sentidos (maconha, LSD, e substâncias advindas de produtos naturais, como cogumelos e plantas). As estimulantes conseguem desencadear alterações nervosas capazes de gerar momentos eufóricos extrapolados - além de serem utilizadas como recurso para tratar problemas de atenção e desordens de cunho neurológico - e despertar o indivíduo 
por tempo abrangente. Exemplos dessas substâncias são a cocaína, crack, tabaco, anfetaminas e, amplamente difundida no mundo, a cafeína (BRASIL, 2017).

O álcool, muito embora seja uma droga lícita e comumente utilizada em meio social, possui capacidades psicotrópicas. Seu uso pode induzir os indivíduos a apresentarem alterações de comportamento, sendo que a intoxicação das mulheres por ele costuma se dar de forma mais rápida, em vista de possuírem quantidades mais elevadas de gordura, menores porcentagens de água e produção inferior de álcool desidrogenase $(A D H)$, enzima responsável pela degradação do álcool no organismo (SILVA et al., 2019). Se caracteriza como fator de risco para uma série de agravos, como os de ordem intencional - violência interpessoal, suicídio - e não intencional, como queimaduras, intoxicações, afogamentos, tuberculose, cânceres, doenças hepáticas, acidentes automobilísticos e vários outros. De todo o álcool consumido no mundo, cerca de um quarto não é registrado, sendo proveniente de fabricações artesanais, adulteradas ou falsificadas (WHO, 2018). Já no Brasil, esse índice é de aproximadamente $15 \%$ e o público que mais consome bebidas alcoólicas de modo abusivo é o masculino, sendo que a faixa etária mais prevalecente é a de 18 a 34 anos (ANDRADE, 2020).

O tabagismo caracteriza-se por ser um dos principais fatores de risco para inúmeras doenças, entre elas os mais variados tipos de cânceres e doenças cardiopulmonares, e causa evitável de mortes. A nível mundial, mais de 7 milhões de pessoas morrem anualmente em decorrência de agravos de saúde provocados pelo tabagismo e, desse total, o Brasil agrega cerca de 150 mil mortes. Em 2018, o valor percentual de fumantes que possuíam 18 ou mais anos de idade era de 9,3\% no total no país. No setor de saúde, o Brasil gasta quase 40 bilhões de reais por ano com doenças derivadas do uso do tabaco (FIGUEIREDO et al., 2017; BRASIL, 2019).

O elevado consumo de analgésicos no Brasil encontra-se fortemente vinculado ao índice altíssimo de prevalência de dor crônica (DC) (cerca de $41 \%$ da população possui essa modalidade de dor). A principal causa de DC costuma ser a atividade desempenhada no trabalho. Para tratamento analgésico, os anti-inflamatórios não esteroidais, somados à dipirona e paracetamol, configuram-se como a mais 
prevalente linha de tratamento. Dentre os analgésicos, também podemos destacar a classe dos opiáceos, utilizados para tratar dores moderadas e intensas, sendo empregados amplamente no tratamento da dor de pacientes oncológicos (BARROS et al., 2019). No Brasil, em 2015, constatou-se que cerca de 4,5 milhões de pessoas já haviam usado opiáceos de forma não prescrita em algum momento de suas vidas (BASTOS et al., 2017).

Dentre as drogas de abuso (drogas que não foram devidamente prescritas por profissional da saúde capacitado para isso), como as anfetaminas, LSD, crack e cocaína por exemplo, podemos destacar a maconha - Cannabis sativa - por ser utilizada desde os primórdios da humanidade e ser a terceira droga mais consumida a nível mundial, sendo o álcool e o tabaco as mais utilizadas, respectivamente (VANJURA et al., 2018). Historicamente, no século XVIII, muito antes de se tornar uma substância ilícita no país, a maconha era produzida em grande escala no Brasil, com o intuito de usá-la, principalmente, para a confecção de cordas nas embarcações portuguesas, gerando lucro e favorecendo a balança comercial (PEREIRA et al., 2018). No Brasil, a maconha é a droga ilícita mais consumida, sendo que cerca de $7,7 \%$ dos brasileiros entre 12 e 65 anos já a utilizaram pelo menos uma vez na vida (BASTOS et al., 2017). Suas propriedades abrangem capacidades psicotrópicas, podendo produzir alucinações e efeitos depressores no sistema nervoso. Além disso, também é, por vezes, utilizada como tratamento para algumas patologias (VANJURA et al., 2018).

O início do consumo de drogas psicoativas costuma se dar na faixa etária de 12 e 24 anos. O ingresso de estudantes nas universidades ao redor do planeta costuma acontecer em meados dessa faixa etária, fator que, pelo fato da universidade representar uma etapa de transição e ampla mudança na vida do indivíduo, coincide com a maior taxa do uso abusivo de psicotrópicos. Dentre as substâncias utilizadas entre universitários, o álcool e o tabaco confirmam-se como as mais utilizadas respectivamente e, dessa forma, concordam com o padrão classificatório mundial de uso dos psicotrópicos (OLASHORE et al., 2018). O uso de psicoativos abrange os sexos masculino e feminino, sendo que tais substâncias podem deflagrar impactos 
negativos na vida pessoal e acadêmica desses estudantes, por conta de ausência nas aulas, atrasos e falta de atenção (SANTOS et al., 2019). Não obstante, drogas lícitas, como o álcool, podem ser fatores de risco para esses estudantes, uma vez que o comportamento e a capacidade de julgamento dos indivíduos podem ser alterados negativamente, levando a atitudes de risco, como a realização de sexo desprotegido (culminando, por vezes, em possível contaminação pelo vírus da imunodeficiência adquirida - HIV - ou gravidez indesejada, além de outras possíveis infecções sexualmente transmissíveis), violência interpessoal e outras problemáticas (WHO, 2018).

Um dos cursos com as vagas mais disputadas no Brasil é o de Medicina. Para conseguir ter a chance de adentrar e se tornar um acadêmico nessa área, o estudante do pré-vestibular necessita de dedicação abrangente aos estudos, de modo a construir e lapidar seus conhecimentos para a prova vestibular. Em meio a esse árduo processo, é frequente que muitos estudantes desenvolvam transtornos de ansiedade, muito estresse e, também, depressão. A exigência emocional, atrelada às cobranças familiares (muitas vezes presentes) para a aprovação são fatores que podem incitar tais transtornos e prejudicar a saúde psicológica do estudante (SANTOS et al., 2017).

Em vista da grande quantidade de fatores que causam estresse no curso de Medicina, a cognição e o psicológico dos acadêmicos são constantemente afetados, além de sua condição fisiológica, deflagrando problemas orgânicos de ordem psiquiátrica e perda na qualidade de vida. Com o intuito de que haja compreensão sobre a gravidade desses fatores, faz-se necessária a ampla compreensão dos mesmos, de modo a encontrar a origem dos problemas para solucioná-los (LIMA et al., 2016). O estresse psicológico costuma associar-se com efeitos acadêmicos negativos, como dificuldade para dormir, uso de substâncias psicotrópicas, esgotamento, diminuição do aprendizado (e consequente impacto negativo na formação), falta de empatia com os pacientes e, até mesmo, ideação suicida (MCLUCKIE et al., 2018). Porém, para obter panorama mais abrangente das problemáticas, é necessário observar outros fatores envoltos ao estudante, como a possibilidade de problemas financeiros, relacionamentos, falta de tempo, grande responsabilidade, suporte e orientação 
inadequada em sua formação, exposição frequente à morte e sofrimento dos pacientes e a outras circunstâncias complexas (HILL et al., 2018). Somado a esses agravos, muitos estudantes do curso de medicina acabam por não procurar ajuda médica com a frequência que deveriam, deixando de resolver as problemáticas que surgem. No geral, somente cerca de 8 a 15\% desses acadêmicos procuram auxílio psiquiátrico no decorrer da graduação, mesmo que sofram constantemente por conta de tais problemas (VASCONCELOS et al., 2015).

\section{OBJETIVO}

Analisar o uso de substâncias psicoativas entre discentes de medicina da Universidade Federal do Amapá em 2018.

\section{MÉTODO}

Estudo transversal quantitativo e qualitativo, que utilizou uma amostra de conveniência, não probabilística, de estudantes universitários. Para coleta de dados a amostra contou com 204 discentes de seis anos do curso de medicina da Universidade Federal do Amapá (UNIFAP). Foi utilizada a parte I do instrumento autoaplicável validado em português "Inventário de Triagem do uso de Drogas - Revisado" (Drug Use Screening Inventory-Revised - DUSI-R) (DE MICHELI e FORMIGONI, 2002), desenvolvido para avaliar e identificar o uso abusivo de substâncias psicoativas, lícitas e ilícitas, e que mede o uso de 13 substâncias psicoativas no último mês. A aplicação ocorreu via formulário on line e os dados obtidos foram organizados e tabulados em planilhas do programa Excel, componente do pacote Office da Microsoft Corporation.

O projeto foi submetido e aprovado pelo Comitê de Ética em Pesquisa (CEP) (CAAE 89616818.2.0000.0003), conforme protocolo da Plataforma Brasil, seguindo os princípios éticos e atendendo as considerações éticas dispostas na resolução ํㅡ 466, de 12 de dezembro de 2012, do Conselho Nacional de Saúde (CNS). 


\section{RESULTADOS}

A análise demonstra que as principais substâncias utilizadas por todas as turmas foram álcool $(67,65 \%)$, analgésicos $(49,51 \%)$ e tabaco (9,80\%). A única substância psicoativa que é consumida pela maioria é o álcool.

Os dados mostram o uso de substâncias psicoativas nos últimos trinta dias por discentes de medicina entre 2013 e 2018, por gênero e tipos de substâncias (Figura 1). O uso de álcool e tabaco é maior em estudantes do gênero masculino $(36,27 \%$ e $7,37 \%$, respectivamente), e o uso de analgésicos é discretamente maior no gênero feminino (25\%).

Figura 1 Mostra o uso de substâncias psicoativas nos últimos trinta dias por discentes de medicina entre 2013 e 2018, por gênero e tipos de substâncias.

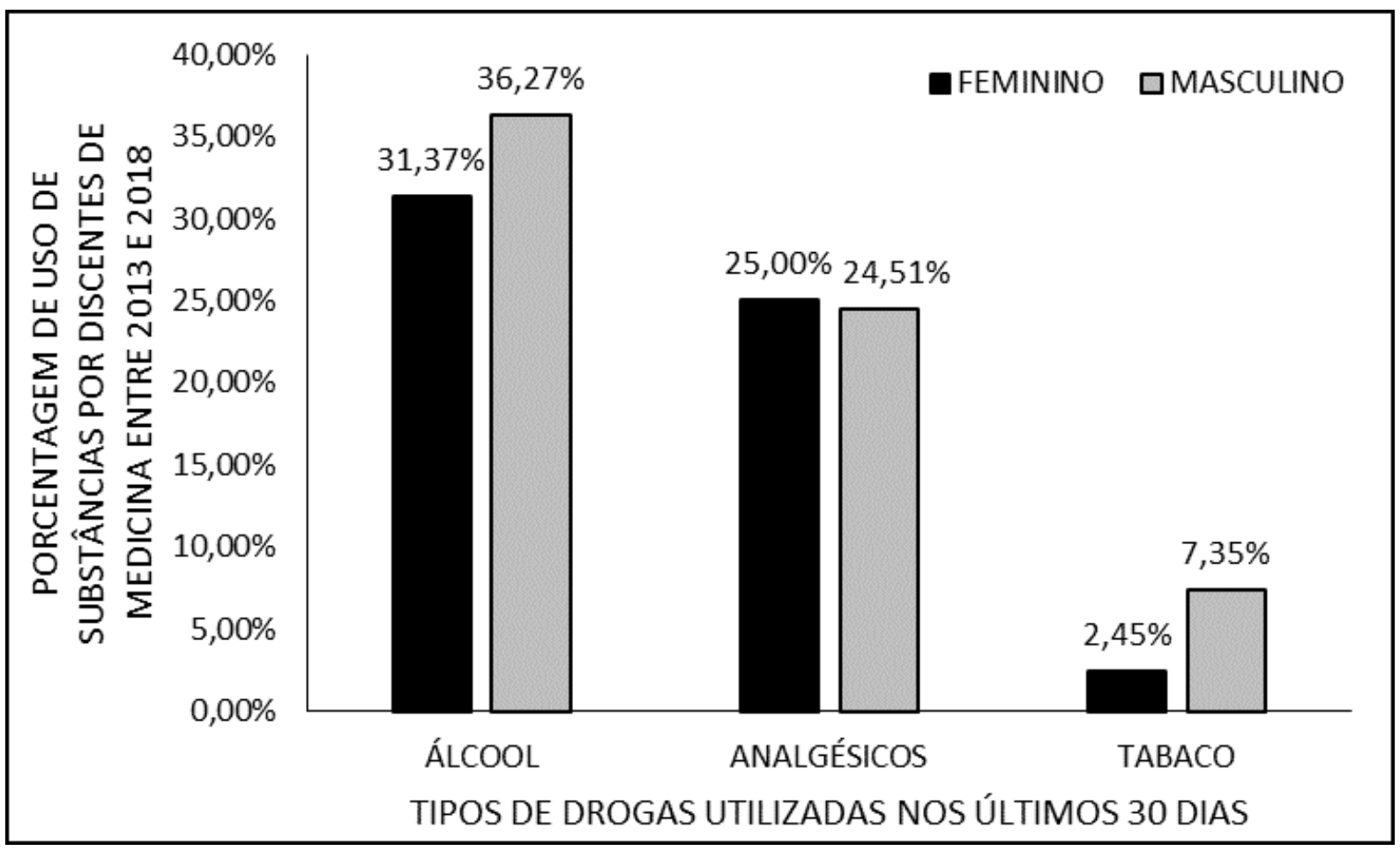

Fonte: Produzido pelos autores com dados da pesquisa.

Quanto a porcentagem e tipos de substâncias psicoativas utilizadas nos últimos trinta dias por discentes de medicina entre 2013 e 2018, por gênero (figura 2), nos homens 
o número se mostra levemente maior (51\%) do que nas mulheres (49\%). Nota-se a variação anual que demonstra essa quase igualdade.

Figura 2 Mostra os tipos de substâncias psicoativas utilizadas nos últimos trinta dias por discentes de medicina entre 2013 e 2018, por gênero.

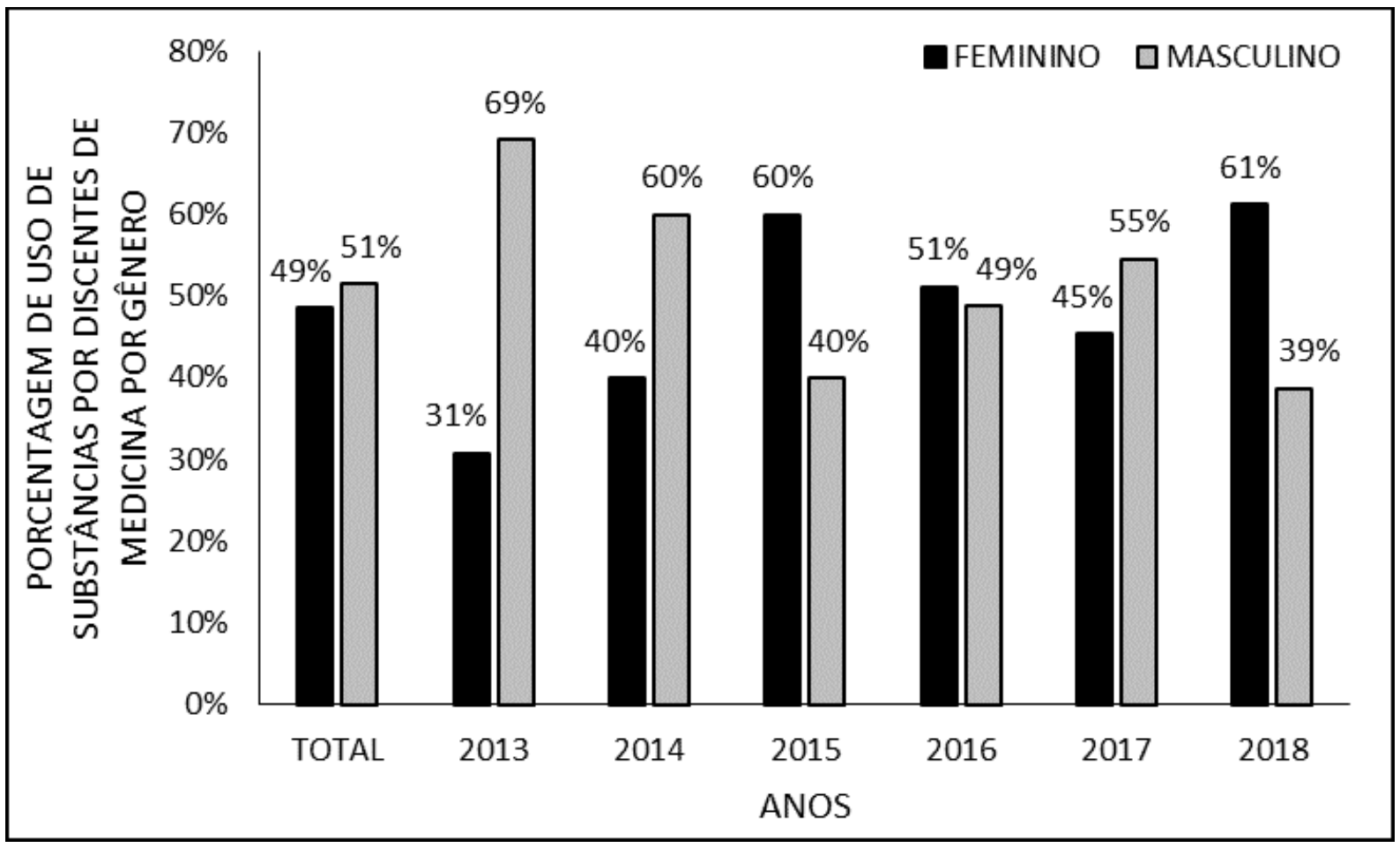

Fonte: Produzido pelos autores com dados da pesquisa.

A figura 3 mostra os tipos de substâncias psicoativas utilizadas nos últimos trinta dias por discentes de medicina entre 2013 e 2018, por ano e por gênero. Nas turmas mais antigas (2013 e 2014) não há uso declarado das substâncias descritas. Na turma de 2015 aparece o uso de ecstasy $(0,49 \%)$, maconha $(0,49 \%)$, alucinógenos $(0,49 \%)$, tranquilizantes $(0,49 \%)$, e outras $(0,49 \%)$, todas pelo gênero masculino. Na turma de 2016 os dados mostram a utilização de todos as substâncias descritas. Neste ano foi declarado o uso de anfetaminas (mulheres 0,98\% e homens 0,49\%), ecstasy (mulheres 0,98\%), cocaína/crack (mulheres 0,49\%), maconha (mulheres 1,47\% e homens 2,94\%), alucinógenos (mulheres 0,49\%), tranquilizantes (mulheres 1,47\% e homens $0,49 \%$ ), opiáceos (mulheres 0,49\%), fenilciclidina (mulheres 0,49\% e homens 
0,49\%), anabolizantes (mulheres 0,49\%), inalantes / solventes (mulheres 0,49\%) e outras (mulheres 0,49\% e homens 0,49\%). No ano de 2017 o uso foi de anfetaminas (mulheres 0,49\% e homens 0,98\%), cocaína / crack (mulheres 0,49\% e homens 0,49\%), maconha (mulheres $0,49 \%$ e homens 0,98\%), alucinógenos (homens 0,49\%), tranquilizantes (mulheres 0,49\% e homens 0,98\%), opiáceos (mulheres 0,49\%), anabolizantes (homens 0,49\%) e outros (mulheres 0,49\%). Em 2018 as substâncias psicoativas declaradas foram anfetaminas (mulheres 0,49\% e homens 1,49\%), ecstasy (homens $0,49 \%$ ), maconha (mulheres $0,49 \%$ e homens $1,47 \%$ ), alucinógenos (homens $0,49 \%$ ), e tranquilizantes (mulheres $0,49 \%$ e homens $0,49 \%$ ). 
Figura 3 Mostra os tipos de substâncias psicoativas utilizadas nos últimos trinta dias por discentes de medicina entre 2013 e 2018, por ano e por gênero

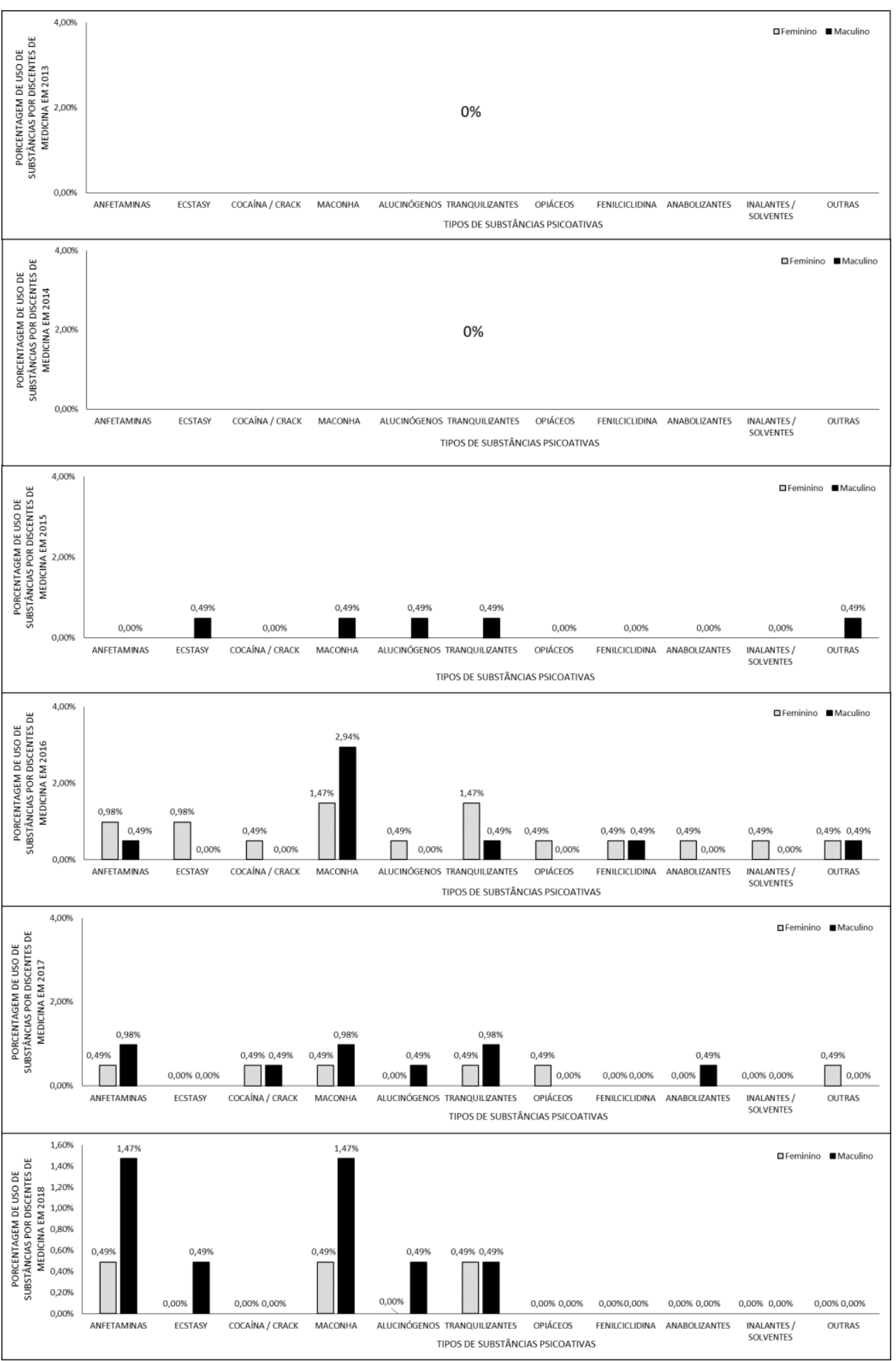

Fonte: Produzido pelos autores com dados da pesquisa. 


\section{DISCUSSÃO}

Em vista da abrupta mudança de vida e da inserção no meio social universitário, o acadêmico passa por um processo de transformação psicológica. Além disso, outros fatores contribuintes para essa modificação orgânica e comportamental são derivados do estresse diário da graduação. Aspectos como a vasta cobrança responsabilidades abrangentes (as quais aumentam com o decorrer do curso), ansiedade, esgotamento, distância da família (para os acadêmicos de outras localidades e, até mesmo, para os que continuam morando com suas famílias, pois a imensa quantidade de conteúdo a ser estudado acaba por privar momentos de confraternização e lazer) incorrem na maior possibilidade de uso de substâncias psicoativas, principalmente o álcool (DELFINO et al., 2018). O uso de psicotrópicos por médicos, estudantes de medicina e profissionais da área da saúde em geral é comum, uma vez que parcela considerável faz ou já fez uso dessas substâncias (TALIH et al., 2018).

Muito embora, segundo estudos, as mulheres acabem por iniciar o uso de substâncias mais precocemente (com o uso de maconha, opióides, ansiolíticos e outros), o sexo masculino predomina em relação ao uso crônico de álcool e tabaco, sendo que, por si só, o quesito "sexo masculino" é atrelado como fator de risco para a utilização de substâncias psicoativas (FERNANDES et al., 2017). Em relação a fatores predisponentes ao uso de psicotrópicos, contata-se que a participação de alunos nos centros acadêmicos e a renda superior a 40 salários mínimos (cerca de 92\% dos alunos que se encaixam nesse quesito fazem uso de álcool, além de que aproximadamente $39 \%$ faz uso de drogas ilícitas) fazem mais uso de tais substâncias (TRINDADE et al., 2018).

Em estudos feitos com comparativos entre algumas universidades da região sudeste e nordeste, o padrão de consumo das principais substâncias psicotrópicas por universitários foi deveras similar a nível de gênero. Na amostra em questão, o maior uso de álcool e maconha ocorreu pelo sexo masculino, com $74,5 \%$ e 10,4\% respectivamente, comparados aos $69,8 \%$ de uso de álcool e 7,9\% de maconha do sexo feminino. (TRINDADE et al., 2018). Com o decorrer do curso e seu consequente avanço de dificuldade e exigência, a utilização de substâncias psicoativas também 
tende a aumentar, uma vez que o estresse, ansiedade, esgotamento e muitos outros fatores negativos também aumentam, levando ao uso mais acentuado desses

Já considerados como fatores de risco para a utilização de psicotrópicos, o índice de uso de substâncias ilegais é maior em homens (FERNANDES et al., 2017). Com o intuito de melhorar sua performance acadêmica (mantendo-os acordados, melhorando seu humor e sua memória, além de aprimorar sua capacidade de concentração e consequente aprendizado) muitos estudantes de medicina utilizam drogas como a ritalina (cloridrato de metilfenidato) e anfetaminas, ambas drogas estimulantes do sistema nervoso. Porém, muito embora apoiem-se nos benefícios dessas drogas para aprimorar seu desempenho, inúmeras são as consequências negativas dessa utilização, como o aumento da pressão sanguínea a níveis perigosos, sensação de euforia, taquipneia (aumento do ritmo respiratório) e outras implicações orgânicas. Em um estudo realizado na Universidade Babol de ciências médicas, constatou-se que, da amostra de 49 estudantes de medicina que faziam o uso de drogas estimulantes, 29 deles eram do sexo masculino, representando um total de aproximadamente $59,2 \%$ do valor amostral (FALLAH et al., 2018).

O uso de substâncias psicoativas entre profissionais médicos e estudantes do curso de medicina é abrangente, e esse uso pode estar atrelado à extrema exigência educativa e profissional. Em vista do amplo acesso às mais variadas drogas disponíveis, há um índice elevado do uso de substâncias prescritas pelos médicos e estudantes de medicina, uma vez que o esgotamento físico e a capacidade de dependência dessas drogas culminam em seu amplo uso. Além disso, ainda que haja técnicas que podem rastrear a utilização de tais drogas, existe uma grande dificuldade de admitir sua utilização e relatar que um colega passa por essa situação. Dessa forma, o uso geral dessas substâncias ocorre de forma ampla (DUMITRASCU et al., 2014).

\section{CONCLUSÕES}

Em vista da mudança de ambiente social, ao adentrar à universidade, o acadêmico passa por uma série de transformações psíquicas, as quais são influenciadas pelo 
meio acadêmico e as interações interpessoais por ele propiciadas. Nesse quesito, o consumo de álcool e de algumas substâncias psicoativas, como a maconha, podem ser incitados.

Nacionalmente, os estudantes pré-vestibulandos enfrentam grandes desafios para ingressar no curso de Medicina, uma vez que suas vagas são muito disputadas e fazse necessária grande dedicação aos estudos para poder ser aprovado. Por conta de tais dificuldades, muitos acabam desenvolvendo ansiedade, estresse e transtornos de ordem psíquica.

Por conta das inúmeras exigências e responsabilidades do curso de Medicina, vários fatores negativos acabam sendo deflagrados na vida do estudante, como a ansiedade, estresse, esgotamento, dificuldade para dormir e outros problemas orgânicos.

Com o intuito de prolongar horas de estudo e concentração nas atividades da Medicina, muitos acadêmicos fazem uso de substâncias psicoativas ilícitas para aumentarem sua performance, porém, podem obter inúmeras consequências fisiológicas negativas por conta disso.

$\mathrm{Na}$ Universidade Federal do Amapá, entre os discentes de Medicina, notou-se que o uso de psicotrópicos se dá principalmente pela utilização de álcool e analgésicos. Porém, mesmo que em pequena parte da amostra, também houve uso de outras substâncias, como tranquilizantes, tabaco, ecstasy, cocaína, crack e outras.

A predominância do uso de álcool e tabaco é do sexo masculino, correspondendo aos parâmetros mundiais, uma vez que o quesito "sexo masculino" é considerado fator de risco para a utilização de substâncias psicoativas. Porém, nota-se que o uso de analgésicos é maior entre o sexo feminino, sendo que, quanto às demais substâncias - principalmente maconha - o índice de uso é similar.

No contexto médico, por conta do acesso facilitado às drogas de prescrição, a utilização das mesmas é muito mais ampla nesse público de profissionais e acadêmicos, sendo que o uso de tais substâncias é, por vezes, ocultado e existe uma dificuldade em falar sobre e procurar auxílio. 


\section{REFERÊNCIAS}

ANDRADE, A. G. D. Álcool e a Saúde dos Brasileiros: Panorama 2020. São Paulo: CISA 2020. 152p.

Disponível em: $<$ https://cisa.org.br/images/upload/Panorama_Alcool_Saude_CISA2020.pdf >.

BARROS, G. A. M. D. et al. Uso de analgésicos e o risco da automedicação em amostra de população urbana: estudo transversal. Rev Bras Anestesiol., v. 69, n. 6, p. 529-536, 2019.

BASTOS, F. I. P. M. et al. III Levantamento Nacional sobre o uso de drogas pela população brasileira. Rio de janeiro RJ: ICICT/Fiocruz, 2017. 528p. Disponível em: $<$

https://www.arca.fiocruz.br/bitstream/icict/34614/1/II\%20LNUD_PORTUGU\%c3\%8a S.pdf $>$.

BRASIL. Substâncias psicoativas e seus efeitos. Brasilia DF: SENAD: 24 p. 2017. Vigilância de fatores de risco e proteção para doenças crônicas por inquérito telefônico. Brasilia DF: Ministério da Saúde: 131 p. 2019.

DE MICHELI, D.; FORMIGONI, M. L. O. S. Psycometric properties of the Brazilian version of DUSI (Drug Use Screening Inventory). Alcoholism: Clinical and Experimental Research, v. 26, p. 1523-1528, 2002.

DELFINO, N. H. et al. Expectativas e perfil do uso de álcool em acadêmicos de medicina. Arq. Catarin Med., v. 47, n. 4, p. 132-145, 2018.

DINIZ, A. et al. Uso de substâncias psicoativas em idosos: uma revisão integrativa. Revista Psicologia: Teoria e Prática, v. 19, n. 2, p. 23-41, 2017.

DUMITRASCU, C. I. et al. Substance use among physicians and medical students. Medical Student Research Journal, v. 3, p. 26-35, 2014. 
FALLAH, G. et al. Stimulant use in medical students and residents requires more careful attention. Caspian J Intern Med, v. 9, n. 1, p. 87-91, 2018.

FERNANDES, T. F. et al. Uso de susbstâncias psicoativas entre universitários brasileiros: perfil epidemiológico, contextos de uso e limitações metodológicas dos estudos. Cad. Saúde Colet., v. 25, n. 2, p. 498-507, 2017.

FIGUEIREDO, V. C.; TURCI, S. R. B.; CAMACHO, L. A. B. Controle do tabaco no Brasil: avanços e desafios de uma política bem sucedida. Cad. Saúde Pública, v. 33, p. 54-56, 2017.

HILL, M. R.; GOICOCHEA, S.; MERLO, L. J. In their on words: stressors facing medical students in the millenial generation. Medical Education Online, v. 33, p. 1-10, 2018.

LIMA, R. L. D. et al. Estresse do estudante de medicina e rendimento acadêmico. Revista Brasileira De Educação Médica, v. 40, n. 4, p. 678-684, 2016.

MCLUCKIE, A. et al. The relationship between psychological distress and perception of emotional support in medical students and residents and implications for educational institutions. Acad. Psychiatry, v. 42, n. 1, p. 41-47, 2018.

OLASHORE, A. A. et al. Psychoactive substance use among firstyear students in a Botswana university: pattern and demographic correlates. BMC Psychiatry, v. 18, $n$. 270, p. 1-9, 2018.

PEREIRA, J. R. et al. Cannabis Sativa: aspectos relacionados ao consumo de maconha no contexto brasileiro. RAHIS, v. 15, n. 1, p. 1-16, 2018.

SANTOS, D. D. M. et al. Use of psychoactive substances among university students. Revista Eletrônica Saúde Mental Álcool Drog, v. 15, n. 3, p. 1-9, 2019.

SANTOS, F. S. et al. Estresse em estudantes de cursos preparatórios e de graduação em medicina. Revista Brasileira De Educação Médica, v. 41, n. 2, p. 194-200, 2017. 
SILVA, M. D. G. B. D.; LYRA, T. M.; DINIZ, G. T. O padrão de consumo de álcool entre as usuárias das unidades de saúde da família no município do Recife (PE). Saúde Debate, v. 42, n. 122, p. 836-847, 2019.

TALIH, F. et al. Examining burnout, depression, and attitudes regarding drug use among lebanese medical students during the 4 years of medical school. Academic Psychiatry, v. 42, n. 2, p. 288-296, 2018.

TRINDADE, B. P. D. A.; DINIZ, A. V.; JÚNIOR, A. R. S.-. Uso de drogas entre estudantes universitários: uma perspectiva nacional. Revista de Medicina e Saúde de Brasília, v. 7, n. 1, p. 52-60, 2018.

VANJURA, M. D. O. et al. Drogas de abuso: maconha e suas consequências. Rev Cient FAEMA, v. 9, p. 565-569, 2018.

VASCONCELOS, T. C. D. et al. Prevalência de sintomas de ansiedade e depressão em estudantes de medicina. 39, n. 1, p. 135-142, 2015.

WHO. Global status report on alcohol and health 2018. WHO, 2018. $472 p$.

Disponível em:

https://apps.who.int/iris/bitstream/handle/10665/274603/9789241565639-eng.pdf >.

Enviado: Maio, 2020.

Aprovado: Maio, 2020. 